\title{
The Rotterdam Scan Study: design and update up to 2012
}

\author{
M. Arfan Ikram • Aad van der Lugt • Wiro J. Niessen • \\ Gabriel P. Krestin - Peter J. Koudstaal - Albert Hofman • \\ Monique M. B. Breteler • Meike W. Vernooij
}

Received: 4 September 2011/Accepted: 6 October 2011/Published online: 16 October 2011

(C) The Author(s) 2011. This article is published with open access at Springerlink.com

\begin{abstract}
Neuroimaging plays an important role in etiologic research on neurological diseases in the elderly. The Rotterdam Scan Study was initiated as part of the ongoing Rotterdam Study with the aim to unravel causes of neurological disease by performing neuroimaging in a population-based longitudinal setting. In 1995 and 1999 random subsets of the Rotterdam Study underwent neuroimaging, whereas from 2005 onwards MRI has been implemented into the core protocol of the Rotterdam Study. In this paper, we discuss the background and rationale of the Rotterdam Scan Study. We also describe the imaging protocol and
\end{abstract}

M. A. Ikram ( $₫)$ · A. Hofman · M. M. B. Breteler .

M. W. Vernooij

Department of Epidemiology, Erasmus MC University Medical

Center, P.O. Box 2040, 3000 CA Rotterdam,

The Netherlands

e-mail: m.a.ikram@erasmusmc.nl

M. A. Ikram · A. van der Lugt - G. P. Krestin · M. W. Vernooij Department of Radiology, Erasmus MC University Medical Center, Rotterdam, The Netherlands

\section{W. J. Niessen}

Biomedical Imaging Group Rotterdam, Erasmus MC University Medical Center, Rotterdam, The Netherlands

W. J. Niessen

Faculty of Applied Sciences, Delft University of Technology, Delft, The Netherlands

P. J. Koudstaal

Department of Neurology, Erasmus MC University Medical Center, Rotterdam, The Netherlands

M. M. B. Breteler

DZNE, German Center for Neurodegenerative Diseases,

Bonn, Germany post-processing techniques, and highlight the main findings to date. Finally, we make recommendations for future research, which will also be the main focus of investigation in the Rotterdam Scan Study.

Keywords Epidemiology - Population-based · Risk factors · Neuroimaging · Cohort study - Dementia . Stroke $\cdot$ Alzheimer's disease $\cdot$ Microbleeds ·

White matter lesions - Infarcts - Cerebral blood flow . Diffusion tensor imaging · Genetics

\section{Introduction}

Neurologic diseases in the elderly, such as dementia and stroke, will pose an ever increasing burden on societies over the next couple of decades [1-4]. However, effective therapeutic or preventive strategies are lacking. In order to develop such strategies, knowledge on the etiology of these diseases is essential. A feature of neurodegenerative diseases is that morphologic brain pathology may be already present years before clinical onset and can be visualized using magnetic resonance imaging [5-10].

Realizing this potential benefit, already in the 1990 s various population-based studies implemented neuroimaging to study the preclinical brain changes that ultimately lead to or may indicate an increased risk of developing clinically manifest diseases, such as dementia and stroke [7, 11-19]. However, most studies implemented neuroimaging in only a subset of their population leading to limited sample sizes. More importantly, over the course of the last two decades MR imaging has undergone a dramatic improvement in hardware and software leading to higher field strengths, higher resolution, shorter scanning times, and more sensitive sequences. Furthermore, digital imaging techniques have 
led to a new field of research aimed at automating and increasing through-put of image processing for better visualization and quantification of imaging findings. Taken together, these developments now allow for performing neuroimaging in larger sample sizes and using state-of-theart imaging and processing techniques. In turn, this has opened the way for more in depth and thorough investigation of (more subtle) brain changes that can lead to neurological diseases.

It was in this light, that in 1995 the Rotterdam Scan Study was initiated to investigate risk factors and risk indicators of neurological diseases in the elderly using MR imaging to visualize the underlying brain changes and brain pathology. In 1995 and 1999, random subsets of the Rotterdam Study underwent neuroimaging off site in clinical scanners. From 2005 onwards, the Rotterdam Scan Study has been embedded within the core protocol of the Rotterdam Study. This was possible due to installation of a dedicate research scanner on site.

The purpose of this paper is to give a general outline of the study population, scanning protocol, image post-processing and to discuss the main findings of the Rotterdam Scan Study, with the main focus on the period from 2005 to 2011.

\section{Design and study population}

The source population of the Rotterdam Scan Study originates from the Rotterdam Study [20-23], which is a population-based study in the Netherlands and aims to investigate causes and determinants of chronic diseases in the elderly. The Rotterdam Study (RS I) was initiated in 1990 with 7,983 participants aged 55 years and over, who were interviewed and underwent physical exam at baseline and during follow-up visits every 3-4 years. In 2000 the cohort was expanded by 3,011 persons (RS II), who were aged 55 and over at that time. In 2006 the cohort was further expanded by 3,932 persons aged 45 years and over (RS III). The whole cohort undergoes re-examinations every 3-4 years. The total Rotterdam Study population encompasses 14,926 persons.

Figure 1 shows an overview of the various Rotterdam Study cohorts, the time of their (re-)examination visits, and the implementation of MRI-scanning in the core protocol of the Rotterdam Study in 2005. Initially, we invited random persons from the second visit of RS II to undergo MRI. Subsequently, we have scanned all eligible and consenting participants from the first visit of RS III and fifth visit of RS I. Currently, persons from the third visit of RS II are undergoing scanning. For 2012, participants from RS III are scheduled to be re-invited. Because the throughput of performing MR imaging has been higher than that of the Rotterdam Study (56 MRI slots per week versus 36 slots for regular study center visits), we were able to invite additional subsets for re-scanning. As such, we reinvited participants from RS I in 2006, RS II in 2008, and RS III in 2010 outside their regular visits for the Rotterdam Study. As a result, some of the participants are already undergoing their third MRI-exam.

Of all persons taking part in the Rotterdam Study, those who are demented or with MRI contra-indications are considered not eligible for the Rotterdam Scan Study. Furthermore, persons suffering from claustrophobia are also not considered further. Therefore, as of January 2011, a total of 5,886 brain MR-scans have been obtained on the research scanner. This includes multiple scans from the same person.

\section{Scan protocol}

In 2005, a 1.5T MRI unit (General Electric Healthcare, Milwaukee, USA, software version $11 \times$ ) dedicated to the research project was installed in the Rotterdam Study research center. Besides the possibility of high throughput image acquisition, this enabled us to maintain acquisition parameters unchanged by excluding software or hardware upgrades in order to ensure data stability and comparability over time. The MRI unit was fitted with a dedicated 8-channel head coil (best coil configuration available at time of installation) and the possibility for parallel imaging using the array spatial sensitivity encoding technique (ASSET).

Maximum total examination time (from arrival of one participant in the MRI suite until the next) was set at $45 \mathrm{~min}$, in order to accommodate the MRI acquisition into the generic workflow of the Rotterdam Study. We therefore designed a 30 min brain imaging protocol that balanced the restrictions of time, costs and inconvenience for the participants with the relevance and quality of the acquired imaging data. To ensure participant compliance and reproducible image quality (reduce motion artefacts) an acquisition limit of 6 min per sequence was chosen.

To facilitate easier applicability of the current MRI protocol by radiology technicians, we chose to use the standard brain imaging package delivered by the system manufacturer instead of custom developed sequences.

The MRI sequences were chosen based on the primary variables of interest, i.e.:

1. quantitative measures of brain tissue volumes and volumes of various neurostructures (e.g. hippocampus)

2. quantitative assessment of white matter lesions,

3. qualitative assessment of brain infarcts (lacunar and cortical) and microbleeds, 


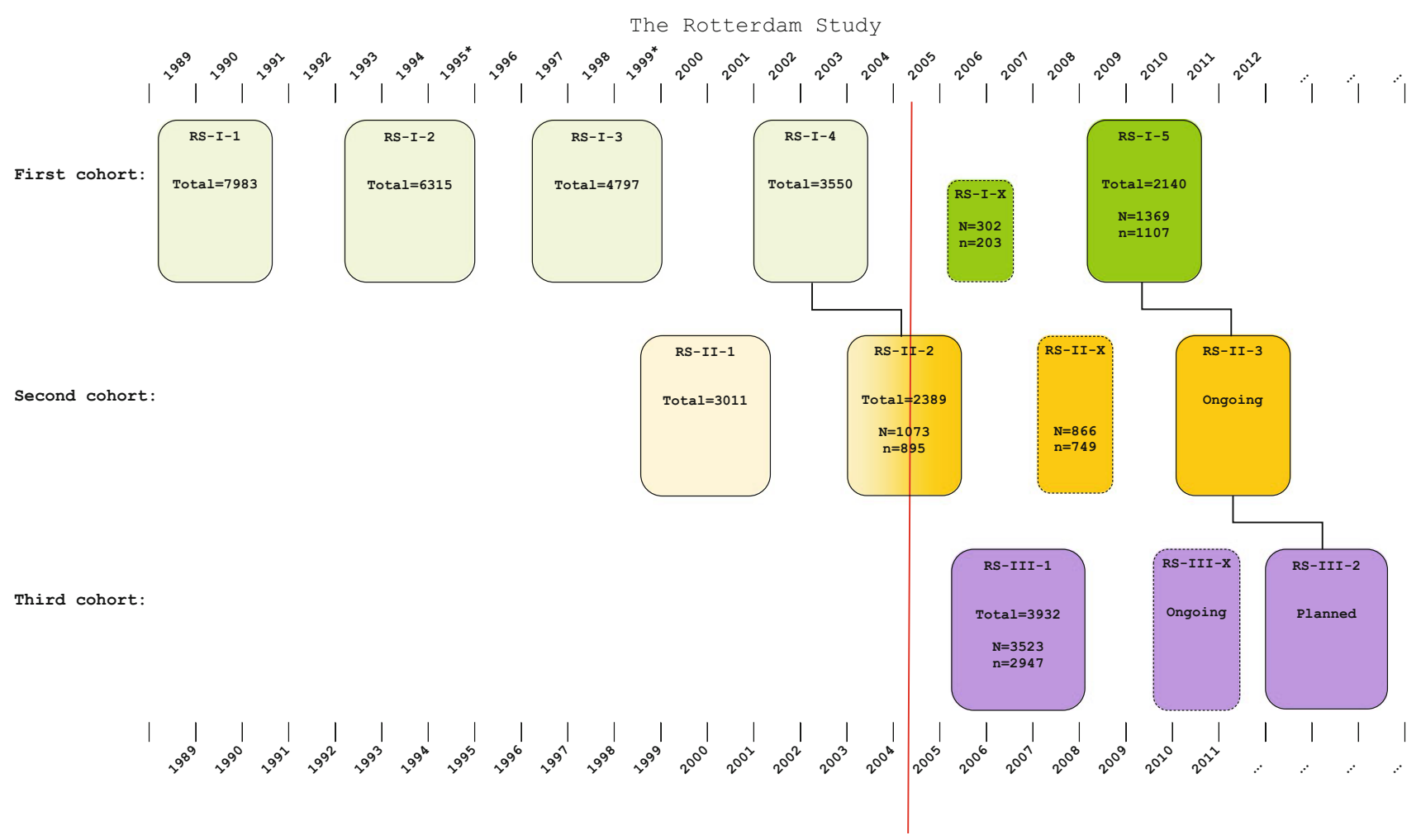

Fig. 1 Overview of the subcohorts and examination visits of the Rotterdam Study, and imaging visits of the Rotterdam Scan Study. Boxes indicate examination visits of the three cohorts of the Rotterdam Study. Boxes with solid colors indicate visits, during which MRI imaging was conducted as part of the core protocol. Examination visits indicated with an ' $X$ ' indicate extra visits during which only MRI was performed. The red vertical line indicates the implementation of MRI on site in the core protocol of the Rotterdam

4. quantitative assessment of white matter microstructural integrity and connectivity,

5. quantitative assessment of total cerebral blood flow.

In designing the protocol, we tried to meet both the time constraint and the contrast and resolution requirements. Where possible, we preferred 3D over 2D sequences because of higher signal-to-noise ratio (SNR), enabling the acquisition of smaller voxel sizes. Yet, acquisition time, sensitivity to motion and blurring artefacts did not allow 3D acquisition in all sequences. For each sequence, we adjusted the imaging parameters during optimization procedures to obtain a specific target resolution with adequate SNR $(\geq 25)$ for tissues in the center of the brain while scan time was limited to $6 \mathrm{~min}$ for each sequence.

The resulting protocol is presented in the Table 1 with all the relevant imaging parameters and the execution order listed. The protocol starts with a three-plane localizer, executed with the shimming option enabled. For subsequent sequences shimming is turned off to accelerate receiver adjustments. Morphological imaging is performed with $\mathrm{T} 1$-weighted $(\mathrm{T} 1 \mathrm{w})$, proton density-weighted (PDw)
Study. In 1995 and 1999 (indicated with *) 567 persons underwent MRI as part of the Rotterdam Scan Study outside the core protocol of the Rotterdam Study. 'Total' indicates the total number of persons taking part in that Rotterdam Study examination visit. ' $N$ ' indicates the number of persons that were eligible (non-demented and no MRI contra-indications) and invited to take part in the Rotterdam Scan Study. ' $n$ ' indicates the number of persons taking part in the Rotterdam Scan Study

and fluid-attenuated inversion recovery (FLAIR) sequences. The combination of different MR contrasts provided by these sequences can be used for automated brain tissue and white matter lesion segmentation (see section on processing). For this purpose, the $\mathrm{T} 1 \mathrm{w}$ scan is acquired in $3 \mathrm{D}$ at high in-plane resolution and with thin slices (voxel size $<1 \mathrm{~mm}^{3}$ ). A $3 \mathrm{D} \mathrm{T} 2 *$-weighted gradient-recalled echo (GRE) scan is used to image cerebral microbleeds. For this sequence a TE $>30 \mathrm{~ms}$ was selected to obtain stronger $\mathrm{T} 2 *$-weighting. For registration purposes, the same slice thickness with a lower in-plane resolution as compared to the 3D T1w scan is used. Parallel imaging is applied for this sequence to stay within the 6 min scan time limit.

Diffusion tensor imaging (DTI) is used to quantitatively assess white matter microstructural integrity [24, 25]. For this 2D DTI scan, we use an echo planar imaging (EPI) readout with gradients $\left(b=1,000 \mathrm{~s} / \mathrm{mm}^{2}\right)$ applied in 25 directions $[24,25]$. The $\mathrm{b}=0 \mathrm{~s} / \mathrm{mm}^{2}$ image is collected with NEX $=3$. The number of gradient directions, i.e. 25, was chosen to best fit the optimized protocol by Jones et al. 


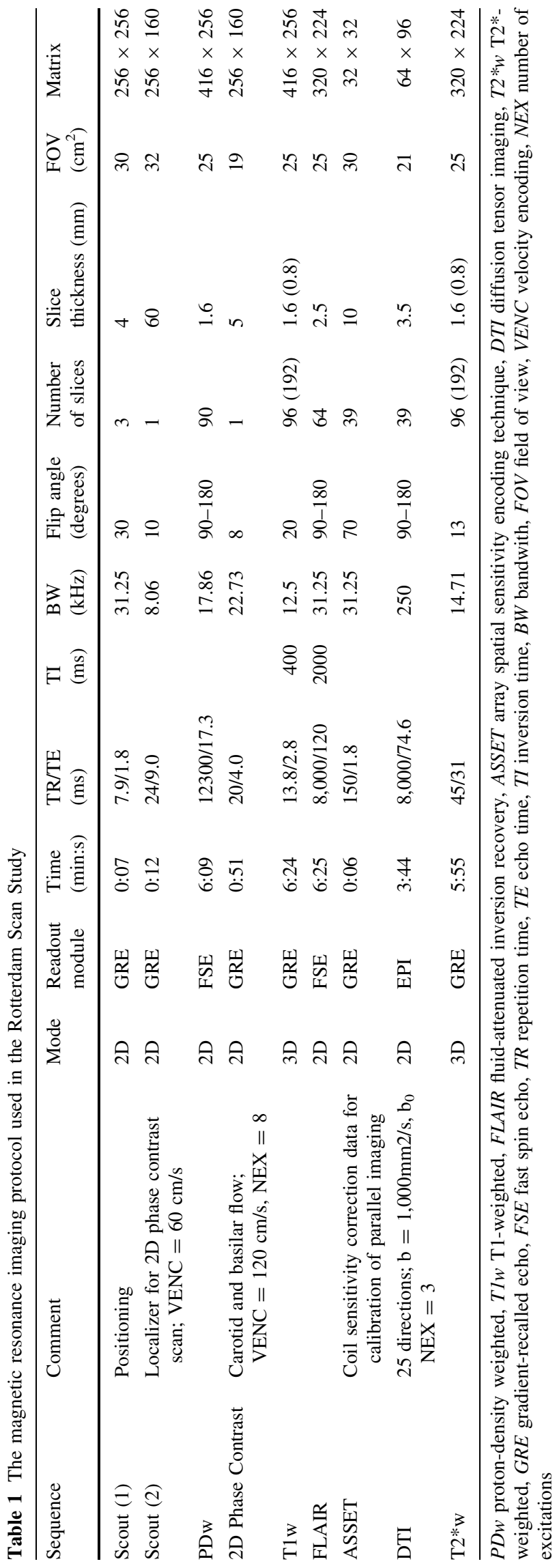

$[24,25]$ whilst remaining within time limits and maximum number of slices permitted by the scanner. To minimize geometrical distortions, the number of frequency encoding points was set to 64 and parallel imaging was applied with an acceleration factor of 2 , with an imaging matrix of $64 \times 96$ and providing a voxel size of $3.3 \times 2.2 \times$ $3.5 \mathrm{~mm}^{3}$.

An ungated 2D GRE phase contrast flow measurement is applied for assessment of total cerebral blood flow [26], which has shown to be fast and accurate [26]. A 2D thick slab projection phase contrast angiographic localizer $(60 \mathrm{~mm}$ thick, velocity encoding $(\mathrm{VENC})=60 \mathrm{~cm} / \mathrm{sec})$ is positioned sagittally to determine the location of the carotid and basilar arteries. Next a thin slice perpendicular to all three vessels at the level of the precavernous internal carotid artery is positioned (VENC $=120 \mathrm{~cm} / \mathrm{s}$, slice thickness $5 \mathrm{~mm}, \mathrm{NEX}=8$ ). Flow velocity data can be calculated from the phase difference images as described before [26].

Figure 2 illustrates an example of all the different sequences acquired in the final protocol. The sequence acquisition order was chosen in a way to provide adequate reconstruction speeds and to eliminate delays. The 3D $\mathrm{T} 2 * \mathrm{w}$ GRE scan was the last sequence executed in the protocol pipeline because of the long reconstruction time necessary for parallel imaging and the resulting lag time in scan execution.

For quality check, a daily quality assessment (measuring transmit gain, center frequency and SNR) is performed by technicians using a phantom. In addition, weekly measurements of echo-planar stability, isocenter reliability and accuracy of absolute scaling along the cardinal axes ( $\mathrm{x}, \mathrm{y}$, z) are performed. Regular scanner maintenance is performed by the manufacturer and results are filed in a $\log$.

Furthermore, interscan reproducibility measurements have been performed by re-inviting study participants ( $n=20-30)$ within on average 2 weeks after initial examination for repeat MRI. Both for brain tissue segmentation as well as for diffusion tensor connectivity analysis, interscan reproducibility has been shown to be very good [27].

\section{Image processing}

Within the context of the Rotterdam Scan Study, a standardized and validated image analysis workflow is being developed to enable the objective, accurate, and reproducible extraction of relevant parameters describing brain anatomy, possible brain pathologies, and brain connectivity from multispectral MRI data. Image processing in the Rotterdam Scan Study has initially been centered around three main goals: First, owing to the sheer size and complexity of the imaging database being generated, we aim to automate the tedious task of manual analysis, both 
Fig. 2 Depiction of the images acquired using the MRI protocol. First row: T1weighted (a), proton-densityweighted (b), and fluid attenuated inversion recovery (c) images. Second row: $\mathrm{T} 2{ }_{-}$ weighted (d) image, sagittal scout for the 2D phase contrast measurement (e), and the resulting flow image (f). Third row: example of an image acquired using diffusion tensor imaging (g), map of fractional anisotropy (h), and map of mean diffusivity (i)
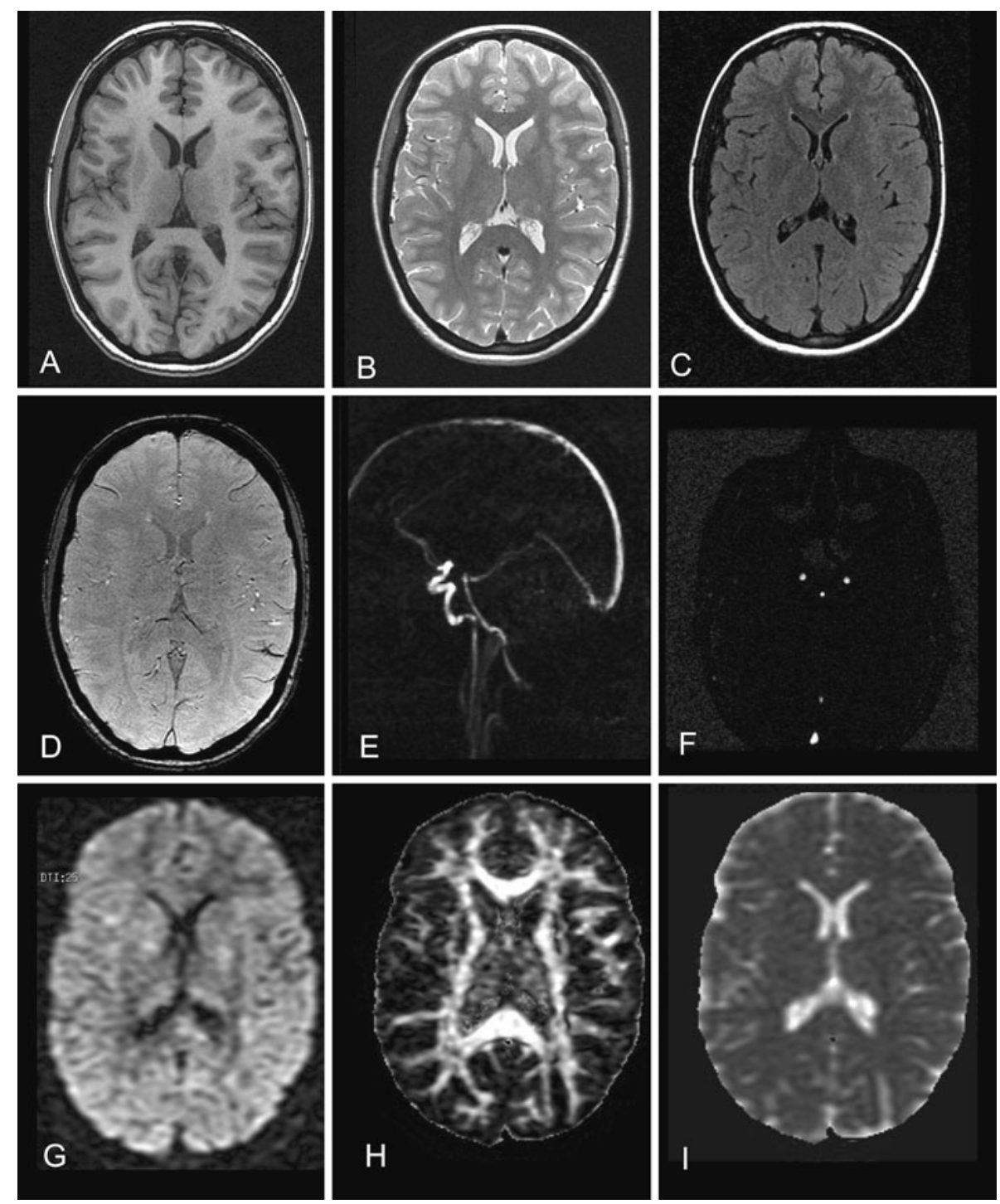

qualitative (e.g. use of rating scales, for example for cortical atrophy) and quantitative (e.g. manual contouring for volume analyses). Second, our goal is to replace qualitative image assessment by quantitative analyses as much as possible. Third, we aim to limit or avoid altogether interand intraobserver variability. In recent years, image processing has been expanded to also allow the extraction of relevant image-derived parameters that would not be feasible manually or cannot be assessed visually.

In the following paragraphs, we briefly describe the different quantitative image analysis methods that have been developed and/or employed within the Rotterdam Scan Study.

Image pre-processing

Prior to analysis, a number of pre-processing steps are performed. For multispectral image analysis, the different scans are spatially registered using rigid registration.
Subsequently, the brain is extracted from the scan. Hereto a manually segmented brain mask, which excludes a.o. the cerebellum, eyes and skull, is non-rigidly registered to the T1-weighted image using Elastix [28].

Finally, scans are corrected for intensity non-uniformity using the N3 method [29]; non-uniformity correction is carried out within the brain mask.

\section{Brain tissue segmentation}

Automated brain tissue segmentation on MRI has received considerable attention [11, 30-39]. An important distinction that can be made is whether methods are supervised (i.e. they depend on annotated training data), or unsupervised. In the Rotterdam Scan Study we have used two types of supervised approaches, both based on k-nearest neighbour $(\mathrm{kNN})$ segmentation. In $\mathrm{kNN}$ segmentation, image voxels are assigned labels (grey matter (GM), white matter (WM), 
cerebrospinal fluid (CSF) or background (BG)) based on the most similar voxels in the training data. Similarity here depends on the distance in normalized MR image intensities. We have both investigated segmentation based on $\mathrm{T} 1 \mathrm{w}$ images, and multispectral MRI data (T1w and PDw images). The two approaches we have used differ in the way that the training data are obtained. In the first approach manual segmentations by two observers of six T1w datasets (the PDw dataset is implicitly segmented after rigid registration to the $\mathrm{T} 1 \mathrm{w}$ datasets), that include labels for GM, WM, CSF, and BG, were used as training data [30, 40]. In the second approach the training data were obtained from the scan to be segmented itself. Hereto, the manually segmented scans are used as atlases and are non-rigidly transformed to the scan, creating probability density maps that indicate the likeliness of each voxel to belong to a certain tissue type. After random selection of likely voxels for each class, and a pruning step to remove outliers, the training samples for WM, GM, CSF and BG are obtained [40, 41].

Both methods have been extensively evaluated within the context of the Rotterdam Scan Study, showing good accuracy and reproducibility [27, 40]. An example of the automated tissue segmentation is shown in Fig. 3.

To facilitate more regionalized analysis of total brain, WM and GM volumes, individual lobes have been segmented. This is achieved by non-rigidly registering a template image in which the lobes have been manually outlined [42-44].

\section{White matter lesion classification}

The brain tissue segmentation methods described above have been complemented with white matter lesion (WML) segmentation [45]. Hereto, both the brain tissue segmentation, and the FLAIR image is used. In the brain tissue segmentation, possible WMLs are misclassified as GM with a ring of WM voxels. In the FLAIR image the WMLs are hyperintense. We therefore process the histogram from the FLAIR image intensities of all voxels that are classified as GM, to estimate the mean and standard deviation of true GM voxels. Subsequently, WML voxels are extracted by intensity thresholding, where the threshold depends on the estimated GM distribution. False positives are removed by excluding voxels which are not sufficiently connected to the white matter. The different parameters (intensity threshold, and quantitative definition of not being sufficiently connected) have been optimized on large reference dataset. The method has been quantitatively evaluated [45] and has successfully been applied to the whole cohort [46]. Visual inspection of the results indicates that the method is robust, with approximately only $4 \%$ of the scans containing false positive or false negative WMLs. Figure 4 demonstrates the automated WML segmentation result.

\section{Brain structure segmentation and shape analysis}

Within the Rotterdam Scan Study we have developed a graph cut framework for neurostructure segmentation [47] combining atlas registration and statistical models of image appearance [48]. As the hippocampus is one of the first regions to be affected by Alzheimer's disease, most work has focused on developing and optimizing the framework for this application.

The developed framework requires annotated training data (atlases), which are used both for atlas registration,
Fig. 3 K-nearest neighbor based tissue segmentation into grey matter ( $r e d$ ), white matter (yellow), cerebrospinal fluid (blue), and background (black)
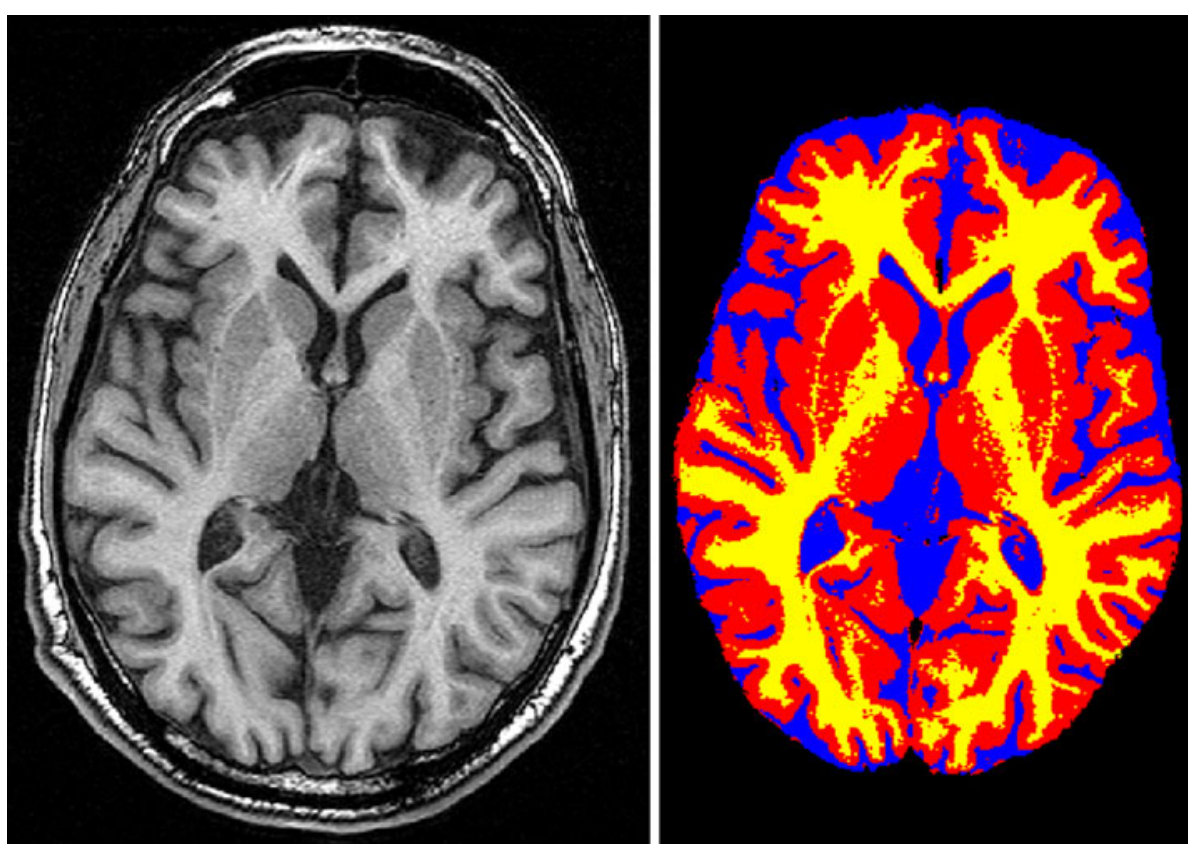
Fig. 4 White matter lesion segmentation (purple), using both the FLAIR image (left) and brain tissue segmentation (Fig. 3) as input
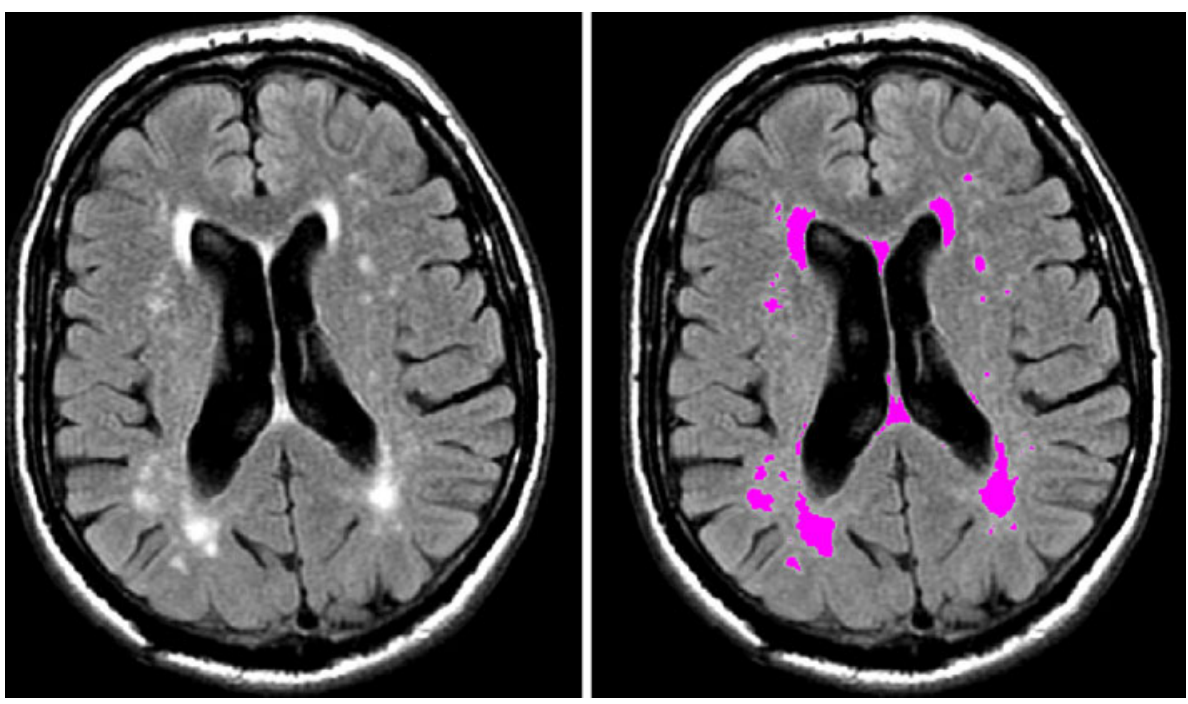

and for training the statistical image appearance models. Two observers manually outlined the hippocampus in twenty datasets, following a well-described protocol [49]. The twenty atlases are nonrigidly registered to an image to be segmented, after which by averaging a spatial probability map is obtained which indicates the likeliness of a voxel to belong to the hippocampus. Within the graph cut framework, this information is complemented by the likeliness that a voxel is part of the hippocampus based on intensity information. Hereto voxel intensities are related to the expected intensity distributions of the hippocampus and the surrounding tissue. The method has been shown to improve on existing manual hippocampus segmentation techniques [48], and has been applied to a number of studies [50,51]. An example of hippocampus segmentation is shown in Fig. 5. The graph cut framework developed for hippocampus segmentation has additionally been used for ventricle segmentation [52], and segmentation of the cerebellum [53]. We are working on further extending the applicability to other neurostructures.

Currently, our focus extends beyond plain volumetry to incorporating shape-based analysis. Therefore, we have developed a method to quantify hippocampal shape, and

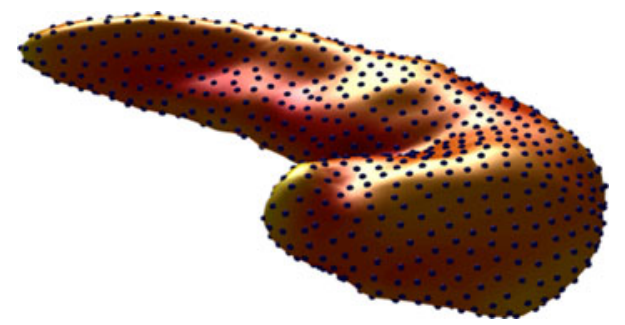

Fig. 5 Hippocampus segmentation, which is used as a basis for both volumetric and shape analysis investigated its potential to predict dementia. Because our aim is prediction, the most suitable datasets are those obtained in 1995 , which have more than 10 years of clinical follow-up. We compared MRI scans of 47 persons who were cognitively normal at scan time and developed dementia during 10-years of follow-up, with 47 age- and gender-matched controls who remained free of dementia. A statistical shape model was built from the 94 segmentation results and was used to predict incident dementia. We found that the combination of hippocampal volume and hippocampal shape performed better than when just using volume [54].

Diffusion tensor imaging: global and tract-based analysis

DTI enables measurement of the microstructural integrity of white matter. Within the Rotterdam Scan Study, a number of image analysis techniques have been employed and developed for the analysis of DTI data. These include conventional global and regional analysis of DTI-derived measures such as Fractional Anisotropy (FA) and Mean Diffusivity (MD) [55], and tract-based analysis of FA [56]. Global and regional analysis of FA and MD has been performed using the FSL toolbox [57], and consisted of Eddy current correction, head motion correction, skull stripping and tensor model fitting. As discussed below, DTI data were registered with the other imaging data to study relations between atrophy, white matter lesions, and DTIderived measures.

Tract-based analysis of DTI enables a more localized comparison of FA and MD between groups. In the Rotterdam Scan Study, tract-based analysis has been achieved using tract-based spatial statistics (TBSS) [58] a technique 
that creates a common skeleton of the white matter tracts from a series of images, onto which for each individual the local maximum FA value is projected. This enables robust voxelwise statistical analysis of the microstructural integrity of white matter across persons [56]. Statistical analysis is performed with multiple linear regressions, adjusting for age, sex and multiple comparisons. In addition, to study relations between macroscopic white matter changes and white matter microstructure, DTI data are aligned with the other MR imaging data.

Diffusion tensor imaging: connectivity analysis

Using deterministic or probabilistic tractography, DTI can also be used to study structural connectivity of the brain. In order to compare structural connectivity across persons in the Rotterdam Scan Study, we developed a novel framework, SAMSCo, which enables construction of weighted structural brain connectivity networks which can be effectively analyzed using statistical methods [59, 60]. The weighted networks are obtained using a minimum cost path (mcp) method with an anisotropic local cost function based on the locally estimated diffusion tensor weighted images. Start and end regions of the mcp were defined by a FreeSurfer segmentation [61, 62] of subcortical structures and cortical parcellation. In proof of principle experiments we showed that the brain connectivity maps contain information on age and sex [59, 60]; we hypothesize that it can also be used for getting valuable insight into normal brain ageing and disease progression. Using a re-scan on 30 persons, good reproducibility of the connectivity maps was shown [27].

\section{Visual ratings}

Scan quality and incidental findings

Each MRI scan that is acquired is visually examined within 1 week after acquisition by a research physician in the Rotterdam Scan Study. During this visual inspection, the MRI scan is rated for quality and the presence and severity of motion artefacts or signal inhomogeneity (for example due to metallic implants) is recorded. Furthermore, each scan is evaluated by trained research physicians for presence of incidental findings, i.e. abnormalities of potential clinical relevance that were previously unknown, that are unexpected and that are unrelated to the purpose of the scan $[63,64]$. All potential findings are recorded in a database and are in a later stage evaluated by an experienced neuroradiologist. The most frequent findings in the Rotterdam Scan Study are aneurysms (1.8\%) and benign primary tumors (1.6\%) [63]. Referral of participants for further medical examination occurs in accordance with an expertdefined protocol [63].

\section{Ischemic small vessel disease on MRI}

Infarcts are rated on FLAIR, proton density-weighted, and T1-weighted sequences. Lacunar infarcts are defined as focal lesions $\geq 3$ and $<15 \mathrm{~mm}$ in size with the same signal characteristics as CSF on all sequences, and (when located supratentorially) with a hyperintense rim on the FLAIR sequence [63]. Lesions $\geq 15 \mathrm{~mm}$ in size, but otherwise similar, are rated as subcortical infarcts. Infarcts showing involvement of cortical gray matter are classified as cortical infarcts.

Cerebral microbleeds

All 3D T2* GRE scans are reviewed for the presence, number, and location of cerebral microbleeds. Microbleeds are defined as focal areas of very low signal intensity on T2*-weighted imaging that are not accompanied by evident signal abnormality on other structural sequences [65]. Microbleed location is categorized into one of three locations: lobar (cortical gray and subcortical or periventricular white matter), deep (deep gray matter: basal ganglia and thalamus, and the white matter of the corpus callosum, internal, external, and extreme capsule), and infratentorial (brainstem and cerebellum) [65]. Intraobserver and interobserver reliabilities for microbleed rating are very good ( $\kappa=0.85-0.87$ [66]) and review of the intial ratings by an experienced neuroradiologist yielded very high accordance as well [66].

Visual check of automated processing performance

Though post-processing for tissue segmentation and structure segmentation takes places fully automated and without user interaction, all end results are visually checked for performance. For example, small motion artefacts in the FLAIR sequence that do not necessitate exclusion of an MRI scan may interfere with white matter lesion segmentation and cause false positive lesions after automated segmentation; or brain masking may result in minimal inclusion of dura or skull. After visual inspection, manual editing of any errors is needed in less than $10 \%$ of scans, depending on the type of post-processing. Furthermore, less than $1 \%$ of scans are excluded based on artefacts that are only discovered after automated post-processing (for example motion or susceptibility artefacts in diffusion tensor images, which are not apparent in the raw unprocessed data). 


\section{Main findings}

Vascular factors and brain pathology

Previous experience with brain MRI in the Rotterdam Study had learned that markers of small vessel disease such as white matter lesions and lacunar infarcts are highly prevalent in the elderly and that these relate to common cardiovascular risk factors [44, 67-78]. In the MRI scans obtained from 2005 onwards, we confirmed the frequent occurrence of WML and infarcts in the elderly and further extended the prevalence and volume estimates to the middle aged population [63]. Furthermore, cerebral microbleeds were added as a new marker of vascular brain pathology, and their interrelationship with 'classic' markers of small vessel disease was examined (see further below). In addition to known classic cardiovascular risk factors, we examined cerebral blood flow as a measure of brain perfusion and studied its determinants and association with cognition and vascular brain disease, as further described below. In line with this, we investigated the association between arterial calcification (measured with computed tomography), a relatively new marker of atherosclerosis, and subclinical vascular disease and found arterial calcification in various vessel beds to be related to both WMLs and lacunar infarcts [79]. Besides our quantitative measures of brain tissue atrophy and lesion volume, DTI added new quantitative information on tissue microstructural integrity, as further elaborated upon below. Finally, in collaboration with research partners in the CHARGE consortium [80], we performed a genome-wide association study of WML burden and were able to identify 6 novel risk-associated SNPs on chromosome 17q25 [81], which we subsequently replicated in a separate Rotterdam Scan Study cohort [46]. After Apolipoprotein E (APOE) this is the first common genetic variant to be robustly associated with brain pathology on MRI. Similar analyses have been undertaken for brain infarcts [82]. These are only the first of more projects that will combine genetic information and imaging markers in the Rotterdam Scan Study.

\section{Cerebral microbleeds}

In 200 Rotterdam Scan Study participants, we showed that the 3D high-resolution T2* GRE sequence detected more microbleeds in more persons, compared with a conventional MRI sequence. When we applied this high-resolution sequence in 1,062 participants, we found that cerebral microbleeds were present in 1 in 5 persons over age of 60 and in over 1 in 3 in persons aged 80 years and older [66]. This prevalence is much higher than reported previously, which in part may be explained by the use of a more sensitive MRI sequence. We recently updated this prevalence estimate for a larger population (4,006 persons, mean age 60.3 years) and found that it still holds [83]. Furthermore, we have consistently shown that risk factors for microbleeds vary according to the location of microbleeds in the brain. Cardiovascular risk factors and markers of ischemic small vessel disease were related to deep or infratentorial microbleeds, whilst $A P O E$ genotype related to strictly lobar microbleeds $[66,83]$. This is indirect evidence that deep or infratentorial microbleeds result from arteriolosclerotic angiopathy, whereas strictly lobar microbleeds are caused by cerebral amyloid angiopathy. This is also corroborated by our finding that spatial distribution of lobar microbleeds in our population follows the known topographic distribution of amyloid angiopathy [84].

The high prevalence of cerebral microbleeds and their potential link with bleeding-prone microangiopathy raised our interest in how these relate to antithrombotic drug use. We found that persons who had used or were using antithrombotic medication significantly more often had cerebral microbleeds [85]. Longitudinal research needs to confirm this association and may unravel a potential link with risk of symptomatic intracerebral hemorrhage. Interestingly, we found a potential link between microbleeds and symptomatic intracerebral hemorrhage when investigating lipid factions as risk factor for both [86].

We also studied the occurrence of incident microbleeds on follow-up MR imaging after an interval of 3-4 years. We found that $10 \%$ of persons developed new microbleeds and that this was strongly related to presence of microbleeds at baseline, but also to various risk factors such as hypertension and smoking [87]. Again, risk factors differed according to the location of new microbleeds, lending further support to the hypothesis on microbleed etiology.

Finally, we recently showed that presence of numerous microbleeds, especially in a strictly lobar location, was associated with worse performance on cognitive tests, even after adjustment for vascular risk factors and other imaging markers of small vessel disease [88]. These results suggest an independent role for microbleed-associated vasculopathy in cognitive impairment.

\section{Cerebral blood flow}

Total cerebral blood flow (tCBF) and total brain perfusion (tCBF per $100 \mathrm{ml}$ brain tissue) were measured with 2D phase contrast imaging as described above. We showed a close relationship between tCBF and markers of the microvasculature, e.g. retinal vessel diameters [77]. In 892 persons aged 60 years and older, we further showed that determinants of $\mathrm{tCBF}$ and total brain perfusion differed largely, due to the large influence of brain volume on tCBF values [89]. Higher pulse pressure, higher body mass 
index, and current smoking were all associated with higher total brain perfusion. Furthermore, persons with low total brain perfusion had significantly more white matter lesions compared to those with high total brain perfusion. The role of tCBF with cognitive performance appeared more complex with brain atrophy either confounding or mediating the association [90].

\section{White matter microstructural integrity}

We have found DTI parameters within white matter lesions and normal-appearing white matter to be associated with cognitive function, even when taking into account volume of white matter lesions and white matter atrophy [55]. This indicates that the deleterious effect of white matter changes on cognition not only depends on lesion burden or amount of atrophy, but also on characteristics that are not easily evaluated by conventional MRI.

Also, we demonstrated that age-related changes in the normal-appearing white matter are primarily explained by white matter atrophy and white matter lesion formation and not by the aging process in itself. Furthermore, we found that white matter atrophy and white matter lesion formation related to loss of integrity in distinct brain regions, indicating that the two processes are not sequential events but are rather independent and thus pathophysiologically potentially different [56].

\section{Future perspectives}

The Rotterdam Scan Study provides a unique environment to study the etiology of neurological diseases in the elderly. Nearly 6,000 persons have already undergone brain MRIscanning and in coming years repeated waves of follow-up examination will ensure a wealth of imaging data, both cross-sectional and longitudinal. So far, the focus of research has been on finding risk factors and determinants of brain pathology. In the coming years we hope to expand the scope of research in several ways, which include novel image sequences, novel post-processing techniques, novel risk factors, and study the relationship of imaging markers with clinical outcomes.

Currently, we are performing pilot studies to investigate the feasibility of resting state functional MRI in the Rotterdam Scan Study. This will allow us to explore not only structural markers of brain pathology, but also functional correlates thereof. The current planning is to fully incorporate BOLDfMRI in the core scanning protocol by the end of 2011.

In the coming years ongoing hardware developments will necessitate upgrading of the scanner. Although there are no current plans to change the scanner, we foresee upgrading to a 3 Tesla scanner in a few years.
Standardized and evaluated automated image processing techniques are crucial in exploiting the rich information that is available in population imaging data. They have enabled a transition from qualitative image interpretation into quantitative imaging. Quantitative imaging is nontrivial; it requires standardization and optimization in all the steps from data acquisition, to data analysis in structured reporting. In the next years, the number of validated quantitative image analysis techniques will further increase, also including more complex measures. Also, the results of these analyses will increasingly be stored in a standardized manner. This will enable a richer characterization of brain anatomy, pathology, connectivity and function. Relating these quantitative image measures to disease status, progression and events, will be a powerful tool for development of novel diagnostic and prognostic quantitative imaging biomarkers.

The standardization of image acquisition and processing protocols also implies that high quality reference data are being acquired. These can be used in a clinical setting to contrast findings in an individual with a reference population.

Our visual ratings currently include infarcts and microbleeds. We are exploring the possibilities of developing a validated visual rating for enlaraged Virchow Robinspaces (perivascular spaces). Evidence suggests that these may be a hallmark of either small vessel disease or atrophy [91, 92].

Finally, the concomitant continuous monitoring of all participants in the Rotterdam Study ensure that we have a wealth of clinical data available, including cognitive performance and the occurrence of dementia and stroke. By the end of 2012, we will already have 6 years of clinical follow-up for the first participants of the Rotterdam Scan Study. In the coming years we hope to investigate how MRI markers of brain pathology relate to these clinical outcomes. It will be especially interesting to investigate how the recently introduced markers, i.e. microbleeds, microstructural integrity, and cerebral blood flow, relate to incident disease, and whether these markers can contribute additional information on top of established markers, such as white matter lesions and infarcts.

Acknowledgments The authors thank all participants, technicians, and research staff of the Rotterdam Scan Study. We are also grateful to the general practitioners of the Ommoord area for their continued support. We thank Piotr Wielopolski and Henri Vrooman for their continued technical assistance during the study. The Rotterdam Scan Study is supported by the Erasmus MC University Medical Center, the Erasmus University Rotterdam, the Netherlands Organization for Scientific Research (NWO) grant 918-46-615, the Netherlands Organization for Health Research and Development (ZonMW), the Research Institute for Disease in the Elderly (RIDE), the Alzheimer's Association (Dr Vernooij, grant NIRG-09-131680; Dr van der Lugt, grant NIRG-08-91393), the Netherlands Heart Foundation (Dr Ikram, 
grant 2009B102), and the Internationaal Parkinson Fonds (Dr Ikram). Further support was obtained from General Electric Health Care.

Open Access This article is distributed under the terms of the Creative Commons Attribution Noncommercial License which permits any noncommercial use, distribution, and reproduction in any medium, provided the original author(s) and source are credited.

\section{References}

1. Hachinski V. Stroke and Alzheimer disease: fellow travelers or partners in crime? Arch Neurol. 2011;68:797-8.

2. Seshadri S, Wolf PA, Beiser A, Au R, McNulty K, White R, D'Agostino RB. Lifetime risk of dementia and Alzheimer's disease. The impact of mortality on risk estimates in the Framingham Study. Neurology. 1997;49:1498-504.

3. Seshadri S, Wolf PA. Lifetime risk of stroke and dementia: current concepts, and estimates from the Framingham Study. Lancet Neurol. 2007;6:1106-14.

4. Thies W, Bleiler L. Alzheimer's disease facts and figures. Alzheimers Dement. 2011;7:208-44.

5. Meyer JS, Kawamura J, Terayama Y. White matter lesions in the elderly. J Neurol Sci. 1992;110:1-7.

6. Pantoni L, Leys D, Fazekas F, Longstreth WT Jr, Inzitari D, Wallin A, Filippi M, Scheltens P, Erkinjuntti T, Hachinski V. Role of white matter lesions in cognitive impairment of vascular origin. Alzheimer Dis Assoc Disord. 1999;13(Suppl 3):S49-54.

7. Fazekas F, Niederkorn K, Schmidt R, Offenbacher H, Horner S, Bertha G, Lechner H. White matter signal abnormalities in normal individuals: correlation with carotid ultrasonography, cerebral blood flow measurements, and cerebrovascular risk factors. Stroke. 1988;19:1285-8.

8. Hachinski VC. The decline and resurgence of vascular dementia. CMAJ. 1990;142:107-11.

9. Fazekas F, Kleinert R, Offenbacher H, Schmidt R, Kleinert G, Payer F, Radner H, Lechner H. Pathologic correlates of incidental MRI white matter signal hyperintensities. Neurology. 1993;43: 1683-9.

10. Pantoni L, Garcia JH. Pathogenesis of leukoaraiosis: a review. Stroke. 1997;28:652-9.

11. DeCarli C, Massaro J, Harvey D, Hald J, Tullberg M, Au R, Beiser A, D'Agostino R, Wolf PA. Measures of brain morphology and infarction in the Framingham heart study: establishing what is normal. Neurobiol Aging. 2005;26:491-510.

12. de Groot JC, de Leeuw FE, Oudkerk M, Hofman A, Jolles J, Breteler MM. Cerebral white matter lesions and subjective cognitive dysfunction: the Rotterdam Scan Study. Neurology. 2001; 56:1539-45.

13. Launer LJ, Oudkerk M, Nilsson LG, Alperovitch A, Berger K, Breteler MM, Fuhrer R, Giampaoli S, Nissinen A, Pajak A, Sans S, Schmidt R, Hofman A. CASCADE: a European collaborative study on vascular determinants of brain lesions. Study design and objectives. Neuroepidemiology. 2000;19:113-20.

14. Launer LJ. Epidemiology of white-matter lesions. Int Psychogeriatr. 2003;15(Suppl 1):99-103.

15. Launer LJ. Epidemiology of white matter lesions. Top Magn Reson Imaging. 2004;15:365-7.

16. Massaro JM, D'Agostino RB Sr, Sullivan LM, Beiser A, DeCarli $\mathrm{C}, \mathrm{Au} \mathrm{R}$, Elias MF, Wolf PA. Managing and analysing data from a large-scale study on Framingham offspring relating brain structure to cognitive function. Stat Med. 2004;23:351-67.

17. Schmidt R, Fazekas F, Offenbacher H, Lytwyn H, Blematl B, Niederkorn K, Horner S, Payer F, Freidl W. Magnetic resonance imaging white matter lesions and cognitive impairment in hypertensive individuals. Arch Neurol. 1991;48:417-20.

18. Schmidt R, Fazekas F, Kapeller P, Schmidt H, Hartung HP. MRI white matter hyperintensities: three-year follow-up of the Austrian Stroke Prevention Study. Neurology. 1999;53:132-9.

19. de Leeuw FE, de Groot JC, Achten E, Oudkerk M, Ramos LM, Heijboer R, Hofman A, Jolles J, van Gijn J, Breteler MM. Prevalence of cerebral white matter lesions in elderly people: a population based magnetic resonance imaging study. The Rotterdam Scan Study. J Neurol Neurosurg Psychiatry. 2001;70: 9-14.

20. Hofman A, Grobbee DE, de Jong PT, van den Ouweland FA. Determinants of disease and disability in the elderly: the Rotterdam Elderly Study. Eur J Epidemiol. 1991;7:403-22.

21. Hofman A, Breteler MM, van Duijn CM, Krestin GP, Pols HA, Stricker BH, Tiemeier H, Uitterlinden AG, Vingerling JR, Witteman JC. The Rotterdam Study: objectives and design update. Eur J Epidemiol. 2007;22:819-29.

22. Hofman A, Breteler MM, van Duijn CM, Janssen HL, Krestin GP, Kuipers EJ, Stricker BH, Tiemeier H, Uitterlinden AG, Vingerling JR, Witteman JC. The Rotterdam Study: 2010 objectives and design update. Eur J Epidemiol. 2009;24:553-72.

23. Hofman A, van Duijn CM, Franco OH, Ikram MA, Janssen HL, Klaver CC, Kuipers EJ, Nijsten TE, Stricker BH, Tiemeier H, Uitterlinden AG, Vernooij MW, Witteman JC. The Rotterdam Study: 2012 objectives and design update. Eur J Epidemiol. 2011; 26:657-86.

24. Jones DK, Simmons A, Williams SC, Horsfield MA. Non-invasive assessment of axonal fiber connectivity in the human brain via diffusion tensor MRI. Magn Reson Med. 1999;42:37-41.

25. Jones DK, Horsfield MA, Simmons A. Optimal strategies for measuring diffusion in anisotropic systems by magnetic resonance imaging. Magn Reson Med. 1999;42:515-25.

26. Buijs PC, Krabbe-Hartkamp MJ, Bakker CJ, de Lange EE, Ramos LM, Breteler MM, Mali WP. Effect of age on cerebral blood flow: measurement with ungated two-dimensional phase-contrast MR angiography in 250 adults. Radiology. 1998;209:667-74.

27. de Boer R, Vrooman HA, Ikram MA, Vernooij MW, Breteler MM, van der Lugt A, Niessen WJ. Accuracy and reproducibility study of automatic MRI brain tissue segmentation methods. Neuroimage. 2010;51:1047-56.

28. Klein S, Staring M, Pluim JP. Comparison of gradient approximation techniques for optimisation of mutual information in nonrigid registration. In: Proceedings of SPIE. Medical imaging: image process; 2005. pp 192-203.

29. Sled JG, Zijdenbos AP, Evans AC. A nonparametric method for automatic correction of intensity nonuniformity in MRI data. IEEE Trans Med Imaging. 1998;17:87-97.

30. Anbeek P, Vincken KL, van Bochove GS, van Osch MJ, van der Grond J. Probabilistic segmentation of brain tissue in MR imaging. Neuroimage. 2005;27:795-804.

31. Blatter DD, Bigler ED, Gale SD, Johnson SC, Anderson CV, Burnett BM, Parker N, Kurth S, Horn SD. Quantitative volumetric analysis of brain MR: normative database spanning 5 decades of life. AJNR Am J Neuroradiol. 1995;16:241-51.

32. Cardenas VA, Ezekiel F, Di Sclafani V, Gomberg B, Fein G. Reliability of tissue volumes and their spatial distribution for segmented magnetic resonance images. Psychiatry Res. 2001; 106:193-205.

33. Chetelat G, Desgranges B, De La Sayette V, Viader F, Eustache F, Baron JC. Mapping gray matter loss with voxel-based morphometry in mild cognitive impairment. Neuroreport. 2002;13: 1939-43.

34. Gur RC, Mozley PD, Resnick SM, Gottlieb GL, Kohn M, Zimmerman R, Herman G, Atlas S, Grossman R, Berretta D, et al. Gender differences in age effect on brain atrophy measured by 
magnetic resonance imaging. Proc Natl Acad Sci USA. 1991;88:2845-9.

35. Jernigan TL, Archibald SL, Fennema-Notestine C, Gamst AC, Stout JC, Bonner J, Hesselink JR. Effects of age on tissues and regions of the cerebrum and cerebellum. Neurobiol Aging. 2001;22:581-94.

36. Jernigan TL, Gamst AC. Changes in volume with age-consistency and interpretation of observed effects. Neurobiol Aging. 2005;26:1271-4; discussion 1275-8.

37. Lemieux L, Hammers A, Mackinnon T, Liu RS. Automatic segmentation of the brain and intracranial cerebrospinal fluid in T1-weighted volume MRI scans of the head, and its application to serial cerebral and intracranial volumetry. Magn Reson Med. 2003;49:872-84.

38. Resnick SM, Pham DL, Kraut MA, Zonderman AB, Davatzikos C. Longitudinal magnetic resonance imaging studies of older adults: a shrinking brain. J Neurosci. 2003;23:3295-301.

39. Sowell ER, Peterson BS, Thompson PM, Welcome SE, Henkenius AL, Toga AW. Mapping cortical change across the human life span. Nat Neurosci. 2003;6:309-15.

40. Vrooman HA, Cocosco CA, van der Lijn F, Stokking R, Ikram MA, Vernooij MW, Breteler MM, Niessen WJ. Multi-spectral brain tissue segmentation using automatically trained k-NearestNeighbor classification. Neuroimage. 2007;37:71-81.

41. Cocosco CA, Zijdenbos AP, Evans AC. A fully automatic and robust brain MRI tissue classification method. Med Image Anal. 2003; 7:513-27.

42. Bokde AL, Teipel SJ, Schwarz R, Leinsinger G, Buerger K, Moeller T, Moller HJ, Hampel H. Reliable manual segmentation of the frontal, parietal, temporal, and occipital lobes on magnetic resonance images of healthy subjects. Brain Res Brain Res Protoc. $2005 ; 14: 135-45$.

43. Bokde AL, Teipel SJ, Zebuhr Y, Leinsinger G, Gootjes L, Schwarz R, Buerger K, Scheltens P, Moeller HJ, Hampel H. A new rapid landmark-based regional MRI segmentation method of the brain. J Neurol Sci. 2002;194:35-40.

44. Ikram MA, Vernooij MW, Hofman A, Niessen WJ, van der Lugt A, Breteler MM. Kidney function is related to cerebral small vessel disease. Stroke. 2008;39:55-61.

45. de Boer R, Vrooman HA, van der Lijn F, Vernooij MW, Ikram MA, van der Lugt A, Breteler MM, Niessen WJ. White matter lesion extension to automatic brain tissue segmentation on MRI. Neuroimage. 2009;45:1151-61.

46. Verhaaren BF, de Boer R, Vernooij MW, Rivadeneira F, Uitterlinden AG, Hofman A, Krestin GP, van der Lugt A, Niessen WJ, Breteler MM, Ikram MA. Replication study of Chr17q25 with cerebral white matter lesion volume. Stroke. 2011. doi: 10.1161/STROKEAHA.111.623090.

47. Boykov Y, Veksler O, Zabih R. Fast approximate energy minimization via graph cuts. IEEE Trans Pattern Anal Machine Intell. 2001;23:1222-39.

48. van der Lijn F, den Heijer T, Breteler MM, Niessen WJ. Hippocampus segmentation in MR images using atlas registration, voxel classification, and graph cuts. Neuroimage. 2008;43: 708-20.

49. den Heijer T, Oudkerk M, Launer LJ, van Duijn CM, Hofman A, Breteler MM. Hippocampal, amygdalar, and global brain atrophy in different apolipoprotein E genotypes. Neurology. 2002;59: $746-8$.

50. den Heijer T, Tiemeier H, Luijendijk HJ, van der Lijn F, Koudstaal PJ, Hofman A, Breteler MM. A study of the bidirectional association between hippocampal volume on magnetic resonance imaging and depression in the elderly. Biol Psychiatry. 2011;70: 191-7.

51. den Heijer T, van der Lijn F, Koudstaal PJ, Hofman A, van der Lugt A, Krestin GP, Niessen WJ, Breteler MM. A 10-year follow-up of hippocampal volume on magnetic resonance imaging in early dementia and cognitive decline. Brain. 2010;133: $1163-72$.

52. van der Lijn F, Vernooij MW, Ikram MA, Vrooman H, Rueckert D, Hammers A, Breteler MM, Niessen WJ. Automated localization of periventricular and subcortical white matter lesions. In: Progress in biomedical optics and imaging-SPIE; 2007. p. 651232 .

53. van der Lijn F, de Bruijne $M$, Hoogendam YY, Klein S, Hameeteman R, Breteler MM, Niessen WJ. Cerebellum segmentation in MRI using atlas registration and local multi-scale image descriptors. In: Proceedings-2009 IEEE international symposium on biomedical imaging: from nano to macro; 2009. pp. 221-224.

54. Achterberg HC, van der Lijn F, den Heijer T, van der Lugt A, Breteler MM, Niessen WJ, de Bruijne M. Prediction of dementia by hippocampal shape analysis lecture notes in computer sciences (including subseries lecture notes in artificial intelligence and lecture notes in bioinformatics); 2010; pp. $42-49$.

55. Vernooij MW, Ikram MA, Vrooman HA, Wielopolski PA, Krestin GP, Hofman A, Niessen WJ, Van der Lugt A, Breteler MM. White matter microstructural integrity and cognitive function in a general elderly population. Arch Gen Psychiatry. 2009;66:545-53.

56. Vernooij MW, de Groot M, van der Lugt A, Ikram MA, Krestin GP, Hofman A, Niessen WJ, Breteler MM. White matter atrophy and lesion formation explain the loss of structural integrity of white matter in aging. Neuroimage. 2008;43:470-7.

57. Smith SM, Jenkinson M, Woolrich MW, Beckmann CF, Behrens TE, Johansen-Berg H, Bannister PR, De Luca M, Drobnjak I, Flitney DE, Niazy RK, Saunders J, Vickers J, Zhang Y, De Stefano N, Brady JM, Matthews PM. Advances in functional and structural MR image analysis and implementation as FSL. Neuroimage. 2004;23(Suppl 1):S208-19.

58. Smith SM, Jenkinson M, Johansen-Berg H, Rueckert D, Nichols TE, Mackay CE, Watkins KE, Ciccarelli O, Cader MZ, Matthews PM, Behrens TE. Tract-based spatial statistics: voxelwise analysis of multi-subject diffusion data. Neuroimage. 2006;31: 1487-505.

59. de Boer R, Schaap M, van der Lijn F, Vrooman HA, de Groot M, van der Lugt A, Ikram MA, Vernooij MW, Breteler MM, Niessen WJ. Statistical analysis of minimum cost path based structural brain connectivity. Neuroimage. 2011;55:557-65.

60. de Boer R, Schaap M, van der Lijn F, Vrooman HA, de Groot M, Vernooij MW, Ikram MA, van Velsen EF, van der Lugt A, Breteler MM, Niessen WJ. Statistical analysis of structural brain connectivity. Med Image Comput Comput Assist Interv. 2010;13: $101-8$.

61. Fischl B, van der Kouwe A, Destrieux C, Halgren E, Segonne F, Salat DH, Busa E, Seidman LJ, Goldstein J, Kennedy D, Caviness V, Makris N, Rosen B, Dale AM. Automatically parcellating the human cerebral cortex. Cereb Cortex. 2004;14:11-22.

62. Fischl B, Salat DH, van der Kouwe AJ, Makris N, Segonne F, Quinn BT, Dale AM. Sequence-independent segmentation of magnetic resonance images. Neuroimage. 2004;23(Suppl 1): S69-4.

63. Vernooij MW, Ikram MA, Tanghe HL, Vincent AJ, Hofman A, Krestin GP, Niessen WJ, Breteler MM, van der Lugt A. Incidental findings on brain MRI in the general population. N Engl J Med. 2007;357:1821-8

64. Vernooij MW, Ikram MA, Hofman A, Krestin GP, Breteler MM, van der Lugt A. Superficial siderosis in the general population. Neurology. 2009;73:202-5.

65. Greenberg SM, Vernooij MW, Cordonnier C, Viswanathan A, Al-Shahi Salman R, Warach S, Launer LJ, Van Buchem MA, 
Breteler MM. Cerebral microbleeds: a guide to detection and interpretation. Lancet Neurol. 2009;8:165-74.

66. Vernooij MW, van der Lugt A, Ikram MA, Wielopolski PA, Niessen WJ, Hofman A, Krestin GP, Breteler MM. Prevalence and risk factors of cerebral microbleeds: the Rotterdam Scan Study. Neurology. 2008;70:1208-14.

67. de Leeuw FE, de Groot JC, Oudkerk M, Witteman JC, Hofman A, van Gijn J, Breteler MM. A follow-up study of blood pressure and cerebral white matter lesions. Ann Neurol. 1999;46:827-33.

68. de Leeuw FE, de Groot JC, Oudkerk M, Witteman JC, Hofman A, van Gijn J, Breteler MM. Hypertension and cerebral white matter lesions in a prospective cohort study. Brain. 2002;125: $765-72$.

69. van Dijk EJ, Breteler MM, Schmidt R, Berger K, Nilsson LG, Oudkerk M, Pajak A, Sans S, de Ridder M, Dufouil C, Fuhrer R, Giampaoli S, Launer LJ, Hofman A. The association between blood pressure, hypertension, and cerebral white matter lesions: cardiovascular determinants of dementia study. Hypertension. 2004;44:625-30.

70. van Dijk EJ, Prins ND, Vermeer SE, Vrooman HA, Hofman A, Koudstaal PJ, Breteler MM. C-reactive protein and cerebral small-vessel disease: the Rotterdam Scan Study. Circulation. 2005;112:900-5.

71. Vermeer SE, Den Heijer T, Koudstaal PJ, Oudkerk M, Hofman A, Breteler MM. Incidence and risk factors of silent brain infarcts in the population-based Rotterdam Scan Study. Stroke. 2003; 34:392-6.

72. Vermeer SE, Koudstaal PJ, Oudkerk M, Hofman A, Breteler MM. Prevalence and risk factors of silent brain infarcts in the population-based Rotterdam Scan Study. Stroke. 2002;33:21-5.

73. Vermeer SE, van Dijk EJ, Koudstaal PJ, Oudkerk M, Hofman A, Clarke R, Breteler MM. Homocysteine, silent brain infarcts, and white matter lesions: the Rotterdam Scan Study. Ann Neurol. 2002;51:285-9.

74. Ikram MK, De Jong FJ, Van Dijk EJ, Prins ND, Hofman A, Breteler MM, De Jong PT. Retinal vessel diameters and cerebral small vessel disease: the Rotterdam Scan Study. Brain. 2006; 129:182-8.

75. Ikram MA, van Oijen M, de Jong FJ, Kors JA, Koudstaal PJ, Hofman A, Witteman JC, Breteler MM. Unrecognized myocardial infarction in relation to risk of dementia and cerebral small vessel disease. Stroke. 2008;39:1421-6.

76. Ikram MA, Vrooman HA, Vernooij MW, van der Lijn F, Hofman A, van der Lugt A, Niessen WJ, Breteler MM. Brain tissue volumes in the general elderly population. The Rotterdam Scan Study. Neurobiol Aging. 2008;29:882-90.

77. de Jong FJ, Vernooij MW, Ikram MK, Ikram MA, Hofman A, Krestin GP, van der Lugt A, de Jong PT, Breteler MM. Arteriolar oxygen saturation, cerebral blood flow, and retinal vessel diameters. The Rotterdam Study. Ophthalmology. 2008;115:887-92.

78. Ikram MK, Sim X, Jensen RA, Cotch MF, Hewitt AW, Ikram MA, Wang JJ, Klein R, Klein BE, Breteler MM, Cheung N, Liew G, Mitchell P, Uitterlinden AG, Rivadeneira F, Hofman A, de Jong PT, van Duijn CM, Kao L, Cheng CY, Smith AV, Glazer NL, Lumley T, McKnight B, Psaty BM, Jonasson F, Eiriksdottir G, Aspelund T, Harris TB, Launer LJ, Taylor KD, Li X, Iyengar SK, Xi Q, Sivakumaran TA, Mackey DA, Macgregor S, Martin NG, Young TL, Bis JC, Wiggins KL, Heckbert SR, Hammond CJ, Andrew T, Fahy S, Attia J, Holliday EG, Scott RJ, Islam FM, Rotter JI, McAuley AK, Boerwinkle E, Tai ES, Gudnason V, Siscovick DS, Vingerling JR, Wong TY. Four novel Loci (19q13, $6 \mathrm{q} 24,12 \mathrm{q} 24$, and $5 \mathrm{q} 14$ ) influence the microcirculation in vivo. PLoS Genet. 2010;6:e1001184.

79. Bos D, Ikram MA, Elias-Smale SE, Krestin GP, Hofman A, Witteman JC, van der Lugt A, Vernooij MW. Calcification in major vessel beds relates to vascular brain disease. Arterioscler Thromb Vasc Biol. 2011;31:2331-2337.

80. Ikram MA, Seshadri S, Bis JC, Fornage M, DeStefano AL, Aulchenko YS, Debette S, Lumley T, Folsom AR, van den Herik EG, Bos MJ, Beiser A, Cushman M, Launer LJ, Shahar E, Struchalin M, Du Y, Glazer NL, Rosamond WD, Rivadeneira F, Kelly-Hayes M, Lopez OL, Coresh J, Hofman A, DeCarli C, Heckbert SR, Koudstaal PJ, Yang Q, Smith NL, Kase CS, Rice K, Haritunians T, Roks G, de Kort PL, Taylor KD, de Lau LM, Oostra BA, Uitterlinden AG, Rotter JI, Boerwinkle E, Psaty BM, Mosley TH, van Duijn CM, Breteler MM, Longstreth WT, Jr., Wolf PA. Genomewide association studies of stroke. N Engl J Med. 2009;360:1718-28.

81. Fornage M, Debette S, Bis JC, Schmidt H, Ikram MA, Dufouil C, Sigurdsson S, Lumley T, Destefano AL, Fazekas F, Vrooman HA, Shibata DK, Maillard P, Zijdenbos A, Smith AV, Gudnason H, de Boer R, Cushman M, Mazoyer B, Heiss G, Vernooij MW, Enzinger C, Glazer NL, Beiser A, Knopman DS, Cavalieri M, Niessen WJ, Harris TB, Petrovic K, Lopez OL, Au R, Lambert JC, Hofman A, Gottesman RF, Garcia M, Heckbert SR, Atwood LD, Catellier DJ, Uitterlinden AG, Yang Q, Smith NL, Aspelund T, Romero JR, Rice K, Taylor KD, Nalls MA, Rotter JI, Sharrett R, van Duijn CM, Amouyel P, Wolf PA, Gudnason V, van der Lugt A, Boerwinkle E, Psaty BM, Seshadri S, Tzourio C, Breteler MM, Mosley TH, Schmidt R, Longstreth WT, Decarli C, Launer LJ. Genome-wide association studies of cerebral white matter lesion burden: The CHARGE consortium. Ann Neurol. 2011;69:928-39.

82. Debette S, Bis JC, Fornage M, Schmidt H, Ikram MA, Sigurdsson S, Heiss G, Struchalin M, Smith AV, van der Lugt A, DeCarli C, Lumley T, Knopman DS, Enzinger C, Eiriksdottir G, Koudstaal PJ, DeStefano AL, Psaty BM, Dufouil C, Catellier DJ, Fazekas F, Aspelund T, Aulchenko YS, Beiser A, Rotter JI, Tzourio C, Shibata DK, Tscherner M, Harris TB, Rivadeneira F, Atwood LD, Rice K, Gottesman RF, van Buchem MA, Uitterlinden AG, Kelly-Hayes M, Cushman M, Zhu Y, Boerwinkle E, Gudnason V, Hofman A, Romero JR, Lopez O, van Duijn CM, Au R, Heckbert SR, Wolf PA, Mosley TH, Seshadri S, Breteler MM, Schmidt R, Launer LJ, Longstreth WT, Jr. Genome-wide association studies of MRI-defined brain infarcts: meta-analysis from the CHARGE Consortium. Stroke. 2010;41:210-7.

83. Poels MM, Vernooij MW, Ikram MA, Hofman A, Krestin GP, van der Lugt A, Breteler MM. Prevalence and risk factors of cerebral microbleeds: an update of the Rotterdam Scan Study. Stroke. 2010;41:S103-6.

84. Mesker DJ, Poels MM, Ikram MA, Vernooij MW, Hofman A, Vrooman HA, van der Lugt A, Breteler MM. Lobar distribution of cerebral microbleeds: the Rotterdam Scan Study. Arch Neurol. 2011;68:656-9.

85. Vernooij MW, Haag MD, van der Lugt A, Hofman A, Krestin GP, Stricker BH, Breteler MM. Use of antithrombotic drugs and the presence of cerebral microbleeds: the Rotterdam Scan Study. Arch Neurol. 2009;66:714-20.

86. Wieberdink RG, Poels MM, Vernooij MW, Koudstaal PJ, Hofman A, van der Lugt A, Breteler MM, Ikram MA. Serum Lipid Levels and the risk of intracerebral hemorrhage: the Rotterdam Study. Arterioscler Thromb Vasc Biol. 2011. doi:10.1161/ ATVBAHA.111.234948.

87. Poels MM, Ikram MA, van der Lugt A, Hofman A, Krestin GP, Breteler MM, Vernooij MW. Incidence of cerebral microbleeds in the general population: the Rotterdam Scan Study. Stroke. 2011;42:656-61.

88. Poels MM, Ikram MA, van der Lugt A, Hofman A, Niessen WJ, Krestin GP, Breteler MM, Vernooij MW. Cerebral microbleeds are associated with worse cognitive function. The Rotterdam Scan Study. Neurology. 2011 (in press). 
89. Vernooij MW, van der Lugt A, Ikram MA, Wielopolski PA, Vrooman HA, Hofman A, Krestin GP, Breteler MM. Total cerebral blood flow and total brain perfusion in the general population: the Rotterdam Scan Study. J Cereb Blood Flow Metab. 2008;28:412-9.

90. Poels MM, Ikram MA, Vernooij MW, Krestin GP, Hofman A, Niessen WJ, van der Lugt A, Breteler MM. Total cerebral blood flow in relation to cognitive function: the Rotterdam Scan Study. J Cereb Blood Flow Metab. 2008;28:1652-5.
91. Zhu YC, Dufouil C, Soumare A, Mazoyer B, Chabriat H, Tzourio C. High degree of dilated Virchow-Robin spaces on MRI is associated with increased risk of dementia. J Alzheimers Dis. 2010;22:663-72.

92. Zhu YC, Tzourio C, Soumare A, Mazoyer B, Dufouil C, Chabriat H. Severity of dilated Virchow-Robin spaces is associated with age, blood pressure, and MRI markers of small vessel disease: a population-based study. Stroke. 2010;41:2483-90. 